\title{
Elimination of the amphibian chytrid fungus Batrachochytrium dendrobatidis by Archey's frog Leiopelma archeyi
}

\author{
Phillip J. Bishop ${ }^{1}$, Rick Speare ${ }^{2, *}$, Russell Poulter ${ }^{3}$, Margi Butler ${ }^{3}$, \\ Benjamin J. Speare ${ }^{2}$, Alex Hyatt ${ }^{4}$, Veronica Olsen ${ }^{4}$, Amanda Haigh ${ }^{5}$ \\ ${ }^{1}$ Department of Zoology, University of Otago, PO Box 56, Dunedin 9054, New Zealand \\ ${ }^{2}$ Amphibian Disease Ecology Group, School of Public Health, Tropical Medicine and Rehabilitation Sciences, \\ James Cook University, Townsville, Queensland, Australia \\ ${ }^{3}$ Department of Biochemistry, University of Otago, PO Box 56, Dunedin 9054, New Zealand \\ ${ }^{4}$ Commonwealth Scientific and Industrial Research Organisation (CSIRO), Australian Animal Health Laboratory, \\ Geelong, Victoria, Australia \\ ${ }^{5}$ Waikato Conservancy Office, Department of Conservation, Private Bag 3072, Hamilton, New Zealand
}

\begin{abstract}
Archey's frog Leiopelma archeyi is a critically endangered New Zealand endemic species. The discovery of the emerging infectious disease, chytridiomycosis, in wild populations of this frog raised concern that this disease may drive the species to extinction. Twelve wild-caught Archey's frogs naturally infected with the amphibian chytrid fungus Batrachochytrium dendrobatidis were monitored in captivity by observing clinical signs, measuring weight gain, and performing repeated PCR tests. Eight frogs were treated with topical chloramphenicol, without PCR results being available, for $B$. dendrobatidis at the day of entry of the frog into the trial. Eleven of the 12 frogs (92\%) cleared their infection within 3 mo of capture, even though they were held at $15^{\circ} \mathrm{C}$ and in high humidity, conditions that are ideal for the survival and propagation of B. dendrobatidis. B. dendrobatidis in the remaining frog tested positive for the fungus was eliminated after treatment with topical chloramphenicol. None of the 8 frogs exposed to chloramphenicol showed any acute adverse reactions. Archey's frog appears to have a low level of susceptibility to the clinical effects of chytridiomycosis. Individual frogs can eliminate $B$. dendrobatidis and Archey's frog can apparently be treated with topical chloramphenicol with no acute adverse reactions. However, the small number of specimens treated here requires that more extensive testing be done to confirm the safety of chloramphenicol. The significance of the amphibian chytrid fungus for wild populations of Archey's frog needs to be determined by a longitudinal study in an infected wild population to correlate the presence of $B$. dendrobatidis in individual frogs. Such a study should occur over a period of at least $3 \mathrm{yr}$ with clinical assessment and monitoring of survival, growth and body condition parameters.
\end{abstract}

KEY WORDS: Batrachochytrium dendrobatidis $\cdot$ Chytridiomycosis $\cdot$ Leiopelma archeyi $\cdot$ Elimination · Treatment $\cdot$ Chloramphenicol

\section{INTRODUCTION}

The Leiopelmatidae represent a unique evolutionary lineage among amphibians, and are thought to be the most archaic frogs in the world. These frogs are found only in New Zealand, and all members belong to the genus Leiopelma. Three species are now extinct ( $L$. auroraensis, L. markhami and L. waitomoensis), with only 4 species extant: L. archeyi, L. hamiltoni, L. hochstetteri and L. pakeka. Archey's frog L. archeyi (Fig. 1) is the smallest of the indigenous species (snoutto-vent length $<38 \mathrm{~mm}$ ) and is listed as critically 


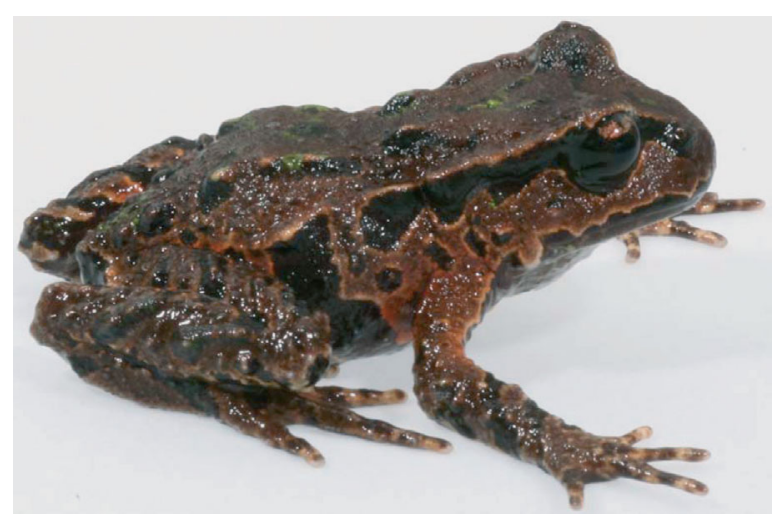

Fig. 1. Archey's frog Leiopelma archeyi (specimen no. HZQ95)

endangered by the International Union for the Conservation of Nature (IUCN 2008). Archey's frog is restricted to 2 regions on the North Island of New Zealand and occurs sympatrically with Hochstetter's frog L. hochstetteri. It prefers to live at a relatively high altitude from about 400 to $1000 \mathrm{~m}$ in moist native forest and is terrestrial and nocturnal, spending most of the day hidden under stones or logs away from streams or creeks. L. archeyi is a terrestrial breeder, laying a small clutch of eggs in a moist site under stones or logs. It exhibits parental care behaviour with the tailed froglets remaining on their father's back for several weeks until metamorphosis is nearly complete (Bell \& Wassersug 2003).

Populations of Archey's frog in the Coromandel Ranges have dramatically declined in recent years with monitored populations decreasing by $88 \%$ from 1996 to 2001 (Bell et al. 2004). Several factors, including the severity and rapidity of the population decline, the geographic spread of the decline (from south to north) and the discovery of frogs with chytridiomycosis (detected by histology), all point to disease as being the major cause of the decline. However, a geographically separate population of Archey's frogs in Whareorino showed no declines although chytridiomycosis had been detected in a dead frog (Bell et al. 2004) and was subsequently confirmed in live frogs by PCR (Smale 2006).

Chytridiomycosis, caused by the amphibian chytrid fungus Batrachochytrium dendrobatidis (Bd), is a disease that has severely affected populations of amphibians in Australia, the Americas, Europe, Africa and New Zealand (Berger et al. 1998, Skerratt et al. 2007). In this paper chytridiomycosis is defined as an infection with $B$. dendrobatidis with 2 classifications: (1) aclinical chytridiomycosis, defined as Bd infection with no apparent clinical signs, and (2) clinical chytridiomycosis, defined as $\mathrm{Bd}$ infection with clinical signs that can range from minor behavioural changes to severe neuro- logical signs and death. In New Zealand chytridiomycosis was identified as the cause of death of introduced Australian Litoria raniformis in the wild at Godley Head near Christchurch in 1999 (Waldman et al. 2001). It was also detected by PCR in the other 2 introduced Australian species, L. ewingii and L. aurea, both in the wild and in captive specimens (Šadic \& Waldman 2004).

In 2006 the New Zealand Department of Conservation detected a $7 \%$ prevalence of $\mathrm{Bd}$ in live frogs at frog monitoring sites in the Whareorino Forest (Smale 2006). Forty-seven dead Archey's frogs collected between 2000 and 2005 tested negative for B. dendrobatidis using real time PCR (Boyle et al. 2004, Hyatt et al. 2007). Due to fears that Archey's frog in Whareorino (the principal population) was faced with an imminent population decline, 100 specimens of this species were transferred to a new location that did not contain frogs and was presumably chytrid-free. This paper reports on (1) the natural history of the Archey's frogs with chytridiomycosis placed in isolation and (2) therapeutic trials with chloramphenicol to eliminate $\mathrm{Bd}$. The paper also reports the use of 2 methods for collecting samples from Archey's frog for PCR.

\section{MATERIALS AND METHODS}

Frogs. Wild Archey's frogs were captured from Whareorino Forest and held in quarantine at the Hamilton Zoo, Hamilton, New Zealand, for 3 mo for disease screening, which included testing for $\mathrm{Bd}$. Twelve (out of 100) frogs that tested positive during this period were sent to the Department of Zoology, University of Otago, Dunedin, for additional study. Frogs arrived in Dunedin on 7 December 2006 and were housed at $15^{\circ} \mathrm{C}$ in plastic containers (310 long $\times$ 210 wide $\times 90 \mathrm{~mm}$ high) with airtight lids on damp paper towels in a room with a day-night cycle of $12 \mathrm{~h}: 12 \mathrm{~h}$. Containers were cleaned once a week and strict hygiene protocols were enforced. Frogs were held in an isolation unit, housed in individual containers and separate gloves were used to handle each frog. All containers and equipment were disinfected with $70 \%$ ethanol. The containers were held in racks covered with black-out cloth, so that when the light was on frogs were in semidarkness to simulate their forest habitat. Frogs were fed once a week on wingless Drosophila melanogaster, crickets, flies and wax moth Galleria mellonella larvae. Prey items added to each container were recorded as were uneaten items. Frogs were inspected daily through the containers, weighed at intervals from $2 \mathrm{wk}$ to $1 \mathrm{mo}$ and tested on multiple occasions for presence of Bd.

Therapeutic trial. After observation in Dunedin for $6 \mathrm{~d}$, a therapeutic trial using chloramphenicol was 
commenced without knowledge of the current PCR results for $\mathrm{Bd}$. Chloramphenicol is effective at killing $\mathrm{Bd}$ in vitro (R. Poulter pers. obs.). For the trial frogs were individually housed in smaller plastic containers $(220 \times 50 \times 45 \mathrm{~mm})$ with the base lined with 2 sheets of paper towel folded flat. The 12 frogs were divided into 3 groups: Group 1, $50 \mathrm{ml}$ distilled water added to the container and replaced daily for $5 \mathrm{~d}$ as the control; Group 2, $50 \mathrm{ml}$ of $10 \mathrm{mg} \mathrm{l}^{-1}$ of chloramphenicol in water replaced daily for $5 \mathrm{~d}_{i}$ Group 3, application of $5 \mathrm{mg}$ of chloramphenicol ointment (Chlorsig 1\%, Sigma) applied to the dorsum daily for $5 \mathrm{~d}$ and $50 \mathrm{ml}$ water added to the container. The $50 \mathrm{ml}$ volume of liquid saturated the paper towels and free liquid was visible. The structure of the trial is shown in Table 1. Containers were disinfected with $70 \%$ ethanol and solutions were changed daily. Frogs were assigned to groups on the basis of body weight so that each group had a range of weights. Trials were completed in 3 batches using 4 frogs each to minimize any adverse effects of the therapeutic compound on these threatened frogs. The initial 2 batches involved 2 control frogs, and 1 frog each in the treatment groups. When no adverse effects were noted in the 2 initial batches, the final batch of 4 frogs was put into 2 treatment groups, 2 frogs per treatment. All frogs were assumed to be positive for chytridiomycosis at the start of each trial and, although swabs were taken to evaluate status at the start of each trial, the testing for chytridiomycosis was not done until the trials were completed. Adverse effects were monitored through daily observations of behaviour, amount of food consumed per week and weight gain.

Sample collection. To test for Bd skin samples were collected either by (1) taking skin swabs from the frogs directly or (2) bathing the frogs in artificial pond water for $15 \mathrm{~min}$ and centrifuging the water within $30 \mathrm{~min}$ of collection (Hyatt et al. 2007). The composition of the artificial pond water was modified slightly from the solution used by Boyle et al. (2004) to eliminate ammonium by adjusting $1000 \mathrm{ml}$ of distilled water with the

Table 1. Leiopelma archeyi. Structure of the therapeutic trial using chloramphenicol solution (Group 2, $\mathrm{n}=4$ ) and chloramphenicol ointment (Group 3, $\mathrm{n}=4$ ). Control frogs were shamtreated (Group 1, $\mathrm{n}=4$ ). Trials were done sequentially to lessen the possibility of any adverse effects on the frogs

\begin{tabular}{|lccc|}
\hline & $\begin{array}{c}\text { Group 1 (sham } \\
\text { treatment) }\end{array}$ & $\begin{array}{c}\text { Group 1 } \\
\text { (solution) }\end{array}$ & $\begin{array}{c}\text { Group 3 } \\
\text { (ointment) }\end{array}$ \\
\hline Trial 1 (13 Dec 06) & 2 & 1 & 1 \\
Trial 2 (21 Dec 06) & 2 & 1 & 1 \\
Trial 3 (9 Jan 07) & 0 & 2 & 2 \\
Total & 4 & 4 & 4 \\
\hline
\end{tabular}

addition of $5 \mathrm{ml}$ of phosphate stock solution $(1.36 \mathrm{~g}$ $\mathrm{KH}_{2} \mathrm{PO}_{4}$ plus $1.74 \mathrm{~g} \mathrm{~K}_{2} \mathrm{HPO}_{4}$ in $100 \mathrm{ml}$ distilled water [total volume]) and $1 \mathrm{ml}$ of calcium-magnesium stock solution $\left(0.37 \mathrm{~g} \mathrm{CaCl}_{2} \cdot 2 \mathrm{H}_{2} \mathrm{O}\right.$ plus $0.51 \mathrm{~g} \mathrm{MgCl}_{2} \cdot 6 \mathrm{H}_{2} \mathrm{O}$ in $50 \mathrm{ml}$ distilled water [total volume], $\mathrm{pH}$ adjusted to 7 with a weak solution of $\mathrm{KOH})$. Skin swabs were stored at $4^{\circ} \mathrm{C}$. At the Hamilton Zoo 3 samples of skin swabs for PCR testing were collected from frogs between 14 September and 12 October 2006, and in Dunedin swabs were collected from all frogs on arrival on 7 December 2006 and at 2, 4, 8, 14 and $19 \mathrm{wk}$ after arrival. Skin swabs were also taken at the conclusion of each $5 \mathrm{~d}$ treatment trial from the individual frogs involved in that trial. Artificial pond water from frog baths were also collected on 2 occasions, one simultaneously with the collection of skin swabs.

PCR testing. PCR tests on all frogs in quarantine at the Hamilton Zoo were performed at the Commonwealth Scientific and Industrial Research Organisation (CSIRO) Australian Animal Health Laboratory (AAHL), Geelong, Australia, using Taqman real time PCR (Boyle et al. 2004). All real time PCR tests on frogs held at Dunedin used the technique of Boyle et al. (2004), but were performed using a LightCycler LC2 (Roche) at the Department of Biochemistry, University of Otago, Dunedin. To test agreement between results from the University of Otago and AAHL, the global reference laboratory for Bd testing, extracts from 99 specimens (including 23 from Leiopelma archeyi) with a $50 \%$ prevalence of positive results were sent to AAHL for PCR testing. Of the 99 samples tested both at the University of Otago and AAHL, $88 \%$ showed qualitative agreement and satisfactory quantitative agreement. In no case were negative samples tested at University of Otago found to be positive when tested at AAHL, giving the PCR test performed at the University of Otago a sensitivity of $100 \%$ relative to the AAHL test. In 12 instances, very low positive counts from the University of Otago were shown to be negative when tested at AAHL. Of the 23 samples of Archey's frogs tested by both groups, 21 tested negative at both sites.

Isolation of Bd. Attempts were also made to culture $\mathrm{Bd}$ from skin flakes that were shed onto gloves during handling using the technique of Longcore (2000) on tryptone/gelatin hydrolysate/lactose (TGhL) agar plates with added antibiotics (ampicillin $100 \mathrm{mg} \mathrm{l}^{-1}$ and tetracycline $25 \mathrm{mg} \mathrm{l}^{-1}$ or kanamycin $80 \mathrm{\mu g} \mathrm{l}^{-1}$ ).

\section{RESULTS}

As mentioned above, 12 of the wild-caught Archey's frogs that were in quarantine at the Hamilton Zoo tested positive for Bd using PCR. For the frogs with at least one positive test, $55.6 \%$ (20 out of 36 ) of their skin 
swabs also tested positive. Only 2 (16.7\%) frogs returned a positive swab on all 3 occasions, while 4 $(33.3 \%)$ and $6(50.0 \%)$ had positive swabs on 2 and 1 of 3 occasions, respectively. The percentage of skin swabs that tested positive on the first, second and third times swabs were taken were $41.7,50.0$ and $75 \%$, respectively (Table 2). Zoospore equivalent increased from the first to the third swab although there was a large variation (Table 2).

One hundred PCR tests were performed on the 12 frogs while in isolation at Dunedin, 9 tests each on 4 frogs and 8 tests each on 8 frogs. Skin swabs were taken on 76 occasions and baths were tested on 24 occasions, with the last set of baths being tested immediately after the swabs had been taken. Only 3 of the 76 skin swabs and none of the baths tested positive. All 3 positive tests were from a single frog (HQZ30) that tested positive on arrival and again 2 wk later. On the day when the second skin swab was taken this frog had been placed into Group 3 of the treatment trial (chloramphenicol ointment). At the end of the $5 \mathrm{~d}$ treatment period a skin swab still tested positive, but at a much reduced level with zoospore equivalents being 176 and 217 pre-trial and 7 at the conclusion of the trial. The frog tested negative in the subsequent 5 tests over 3 mo. For the 11 frogs that tested negative on arrival in Dunedin, excluding HQZ30, the time from the last positive PCR test at the Hamilton Zoo to the first negative test on arrival in Dunedin was $63 \pm 11.5 \mathrm{~d}$ (mean $\pm \mathrm{SD}$ ) with a range from 57 to $85 \mathrm{~d}$. Since the University of Otago PCR test had a sensitivity of $100 \%$ when compared with the AAHL PCR test, the inability to detect $\mathrm{Bd}$ using the University of Otago test was a true negative result. Two samples from HQZ30 tested at both facilities were both positive.

From 7 December 2006, when the frogs first arrived in Dunedin, to February 2007 none of the 12 frogs showed any evidence of clinical disease; all appeared healthy and behaved as normally as expected for the captive situation. However, on 18 April 2007, frog HZQ95 showed epidermal bullae and small $(<2 \mathrm{~mm})$ cutaneous masses with no obvious local inflammation and no systemic signs, consistent with the 'blistering' syndrome described previously in Archey's frog (Waldman 2004, Potter \& Norman 2006). All other frogs were clinically normal. All frogs increased in weight over the 7 mo to April 2007, gaining from 9 to $81 \%$ (mean $\pm \mathrm{SD}=30.1 \pm 20.4 \%$ ) of their original body weight. Frogs treated with chloramphenicol as a solution (Group 2) or as an ointment applied to their backs (Group 3) gained weight after treatment, but the absolute and relative weight gain per month after treatment was reduced (Table 3). However, the changes in weight were not statistically significant. Chloramphenicol treatment did not appear to have any effect on behaviour or to cause visible clinical abnormalities.

A total of 492 attempts at isolating Bd by culture were made and all were negative. However, zoospores were seen on 3 occasions in cultures after $24 \mathrm{~h}$, but failed to establish due to heavy bacterial overgrowth. In spite of antibiotics in the TGhL agar plates bacterial overgrowth was common, with $88 \%$ of the plates overgrown by bacteria and $8 \%$ overgrown by fungi.

\section{DISCUSSION}

This study demonstrates 4 important points: (1) Archey's frog appears to have a low level of susceptibility to the clinical effects of chytridiomycosis, (2) individual Archey's frogs can eliminate Bd, (3) Archey's frog can be treated with topical chloramphenicol with no apparent acute adverse reactions and (4) wild caught Archey's frogs may require multiple PCR tests over 1 mo to detect all frogs with chytridiomycosis.

The infected Archey's frogs not only showed no evidence of clinical disease with chytridiomycosis, but

Table 2. Leiopelma archeyi. PCR results for 12 wild-caught Archey's frogs with aclinical chytridiomycosis. Skin swabs taken on 3 occasions over a period of 1 mo after capture. Individual frogs were classed as positive after 1 positive test. Numbers in brackets are percent of total

\begin{tabular}{|lcccccc|}
\hline Date & $\begin{array}{c}\text { No. of } \\
\text { positives }\end{array}$ & $\begin{array}{c}\text { No. of new } \\
\text { positives }\end{array}$ & $\begin{array}{c}\text { Cumulative no. } \\
\text { of positives }\end{array}$ & $\begin{array}{c}\text { Zoospore } \\
\text { equivalents }\end{array}$ & $\begin{array}{c}\text { Mean } \\
\text { SD }\end{array}$ & Median \\
\hline 14 Sep 06 & $5(41.7 \%)$ & 5 & $5(41.7 \%)$ & 6.11 & 15.88 & 0 \\
28 Sep 06 & $6(50.0 \%)$ & 4 & $9(75.0 \%)$ & 94.64 & 258.73 & 0 \\
12 Oct 06 & $9(75.0 \%)$ & 3 & $12(100.0 \%)$ & 215.33 & 259.82 & 103.5 \\
\hline
\end{tabular}

Table 3. Leiopelma archeyi. Absolute (g) and relative (\%) weight gains per month of frogs before ('Pre') and after ('Post') treatment with chloramphenicol solution (Group 2) or ointment (Group 3), or sham treatment (Group 1)

\begin{tabular}{|ccccccc|}
\hline & \multicolumn{3}{c}{ Weight gain } & \multicolumn{3}{c|}{$\begin{array}{c}\text { Weight gain } \\
\left(\text { (g mo }^{-1}\right)\end{array}$} \\
& $\begin{array}{c}\text { 'P of original weight mo } \\
\text { 'Pre' }\end{array}$ & 'Post' & p-value & 'Pre' $^{\text {'Post' }}$ & p-value \\
\hline Group 1 $(\mathrm{n}=4)$ & 3.23 & 3.24 & 0.99 & 0.055 & 0.068 & 0.80 \\
Group 2 $(\mathrm{n}=4)$ & 11.36 & 2.59 & 0.073 & 0.386 & 0.084 & 0.068 \\
Group 3 $(\mathrm{n}=4)$ & 12.43 & 3.61 & 0.13 & 0.451 & 0.092 & 0.095 \\
\hline
\end{tabular}


also eliminated the fungus. Eleven of the 12 frogs (92\%) tested negative on their first swab on arrival in Dunedin, 8 wk after their third test when $75 \%$ of tests had been positive (Table 2). Susceptible amphibian species infected in the wild and brought into captivity typically retain their infection or die from chytridiomycosis (Banks \& McCracken 2002, Schloegel et al. 2006). Here we use 'susceptible' to mean a species that develops clinical chytridiomycosis when infected with Bd. With this group of Archey's frogs the only positive frog remained positive on 3 subsequent tests, one of which was at the point of entry into a treatment trial with chloramphenicol ointment.

The conditions under which Archey's frogs are housed in captivity to mimic the species' natural environment are ideal for the growth of Bd. In particular, the low temperature of $15^{\circ} \mathrm{C}$ and the high humidity would be expected to result in a high mortality rate in susceptible amphibian hosts. A mortality of $100 \%$ was induced in the susceptible frog species, Mixophes fasciolatus, when the ambient temperature was at $23^{\circ} \mathrm{C}$ or lower, while frogs held at $27^{\circ} \mathrm{C}$ had a lower mortality (Berger 2001, Berger et al. 2004). Similarly, the mortality rate for experimentally infected Litoria chloris was $100 \%$ at temperatures below $24^{\circ} \mathrm{C}$ (Woodhams et al. 2003). Virulence can vary with the strain of Bd (Berger et al. 2005, Retallick \& Miera 2007). Since the wild strain of Bd in New Zealand has not yet been isolated, its virulence has not been assessed. However, since it has been responsible for dieoffs in wild populations of $L$. raniformis introduced from Australia (Waldman et al. 2001), the New Zealand strain of Bd appears to be virulent.

Although the methodology of the treatment trials was good, the lack of positive-tested frogs, apart from one, in test and control groups makes the trial void to assess efficacy. However, the trial is still a valid assessment of the acute adverse effects of chloramphenicol. The only indication of efficacy is that the only frog that had a positive PCR test on entering the trial tested negative after the trial. This frog had been positive on the last 2 (zoospore equivalents of 76 and 72) of the 3 swabs taken prior to shipment to Dunedin and for both of the 2 pre-trial tests (zoospore equivalents of 176 and 217) done at Dunedin. The test at the completion of the $5 \mathrm{~d}$ trial was positive, but zoospore count was reduced (zoospore equivalent of 7); all subsequent tests were negative. Hence, 4 tests had been positive over the $12 \mathrm{wk}$ before treatment and none of 4 tests were positive during the $14 \mathrm{wk}$ after treatment. This result is encouraging in terms of efficacy of treatment. However, since no other individuals in the trial tested positive, the trial should be repeated using frogs with positive PCR at the beginning of the trial.

Archey's frogs tolerated treatment with chloramphenicol both as a solution of $10 \mathrm{mg} \mathrm{l}^{-1}$ in constant con- tact with the undersurface of the frog for $5 \mathrm{~d}$ and as an ointment placed on the back. This study has demonstrated that chloramphenicol appears safe to use in Archey's frogs as medication applied topically. Assessment of safety was based on lack of adverse effects in treated frogs compared with controls through daily observation of behaviour, observation of weekly food consumption and increases in body weight. Although chloramphenicol appeared to have no adverse effects, only a small number (8) of individuals were tested, limiting the opportunity for uncommon adverse effects to be manifested. A larger safety trial would have been desirable, particularly to test more rigorously the effect of treatment on weight gain, but the classification of Archey's frogs as endangered limits access to larger numbers. The dose of chloramphenicol applied in the ointment was estimated as $50 \mu \mathrm{g}$, which for a $2.5 \mathrm{~g}$ frog gives a dose of $20 \mathrm{mg} \mathrm{kg}$. The only experimental study in amphibians used injected chloramphenicol at a high and prolonged dose (125 $\mathrm{mg} \mathrm{kg}^{-1} \mathrm{~d}^{-1}$ for $12 \mathrm{wk}$ ) in Bufo regularis (El-Mofty et al. 2000). In that study progressive haematological changes over time in both red cells and leucocytes were noted. Although the authors reported the development of structural changes consistent with leukaemia in over $20 \%$ of the toads, they did not examine the progression of these changes after cessation of chloramphenicol administration. Hence, their diagnosis of frank leukaemia was unjustified. The relevance of their findings to the clinical situation is uncertain owing to the high prolonged dose of chloramphenicol used and the lack of follow-up when the drug was ceased. The appearance of the blistering syndrome in 1 of the 8 treated frogs in the present study is unlikely to be related to treatment since the syndrome has occurred spontaneously in the wild and captivity in both Archey's frogs (Waldman 2004) and Maud Island frogs Leiopelma pakeka (B. Waldman pers. comm.), and it appeared in the affected frog 2 mo after the chloramphenicol treatment.

Since chloramphenicol is typically well distributed throughout tissues, we assume that chloramphenicol applied topically is absorbed through the amphibian skin. However, the pharmacokinetics of chloramphenicol in amphibians has not been investigated. For Leiopelma spp. chloramphenicol could be used to treat chytridiomycosis and also disease caused by chloramphenicol sensitive bacteria, with the appropriate clinical risk assessment being performed by a veterinarian. Since chloramphenicol is banned in most developed countries for use in food-producing animals, chloramphenicol should not be used to treat frogs intended for human consumption.

This study also illustrates that when wild frogs are bought into captivity and quarantined, repeated tests for Bd over 1 mo may be required to detect all frogs 
positive for the fungus (Table 2). Archey's frog tolerated bath testing for Bd using a modified formula for artificial pond water. This technique was technically easier than swabbing frogs since it involved less handling of these small amphibians. Minimising handling of Archey's frog is recommended since this species appears to have a high incidence of rhabdomyolysis, a condition of unknown aetiology in this species, but which has been associated with physical stress in other animals (Potter \& Norman 2006).

Why did Archey's frog eliminate Bd under conditions that would favour the fungus? In theory several factors could play a protective role including factors external to the amphibian such as temperature, humidity and salts or environmental chemicals, and internal factors such as skin peptides, immunity, bacteria on the skin and unknown intrinsic factors. Seven individuals of Litoria wilcoxi examined in a longitudinal study of a wild population in southeastern Queensland eliminated Bd (Kriger \& Hero 2006). Since infection was mainly acquired during winter and eliminated by summer, the higher temperatures were considered to be the major factor. Experimentally infected L. chloris cleared their infection with $\mathrm{Bd}$ after being held at $37^{\circ} \mathrm{C}$ while frogs at lower temperatures $\left(<24^{\circ} \mathrm{C}\right)$ died (Woodhams et al. 2003). Similarly experimentally infected Pseudacris triseriata cleared Bd when they were held at $32^{\circ} \mathrm{C}$ for $5 \mathrm{~d}$ (Retallick \& Miera 2007). At Dunedin Archey's frogs were confined constantly to a room at $15^{\circ} \mathrm{C}$. Prior to arrival the frogs were held in isolation at the Hamilton Zoo at a mean temperature of $15.5^{\circ} \mathrm{C}$. During shipment between Hamilton and Dunedin, approximately $5 \mathrm{~h}$ in duration, frogs were kept in a coolbox with ice, but temperature was not monitored. The fact that 11 frogs tested negative for Bd within $1 \mathrm{~d}$ of arrival in Dunedin indicates that loss of infection was unlikely to have occurred during this move as typically frogs take at least a few days to revert to testing negative after a successful treatment for chytridiomycosis (R. Poulter, M. Butler \& R. Speare pers. obs.) and as demonstrated by the decline in zoospore equivalents after treatment in the only frog that tested positive in this series. Since the temperature at which this group of Archey's frogs was held was low $\left(15^{\circ} \mathrm{C}\right)$, an elevated temperature cannot explain the elimination of Bd.

Peptides secreted from skin glands onto the skin surface can kill Bd in vitro (Rollins-Smith \& Conlon 2005) and Leiopelma spp. has skin glands that secrete peptides (Green 1988). There is also a statistical association between the activity of skin peptides secreted by some frog species and the fate of their populations in the wild as the chytridiomycosis epidemic has swept through (Woodhams et al. 2006). However, although a frog species may have skin peptides that kill Bd, it may still be highly susceptible, e.g. Litoria caerulea (Berger 2001, Berger et al. 2005). The role of skin peptides in protecting frogs from Bd appears complex and little work has been done in vivo to elucidate this. Bacteria are capable of killing Bd in vitro (Longcore 2000, Harris et al. 2006) and some may have a protective role against chytridiomycosis in wild amphibian populations (Woodhams et al. 2007). Bacterial overgrowth on the skin of Archey's frog has been identified as a problem in specimens housed in the Auckland Zoo (Potter \& Norman 2006). A high proportion (88\%) of our isolation attempts were overgrown by bacteria. In comparison, over the same period 394 isolation attempts from wild-caught Litoria ewingii and L. raniformis had bacterial and fungal contamination at a rate of $37 \%$ and $4 \%$, respectively (R. Speare pers. obs.). The high rate of bacterial contamination, $88 \%$ versus $37 \%$ for Litoria spp., in our attempts to isolate $B$. dendrobatidis indicates that bacteria resistant to ampicillin and kanamycin or tetracycline were more prevalent on the skin of this group of Archey's frogs than Litoria spp. Perhaps the presence of skin bacteria may have played a role in the elimination of Bd. Other theoretical causes for elimination of chytridiomycosis from individual amphibians, including an acquired immune response, have not been investigated. Archey's frog is an interesting model for elimination of $\mathrm{Bd}$.

The lack of clinical disease in Archey's frogs plus the elimination of Bd by the majority of frogs is an important finding as it suggests that the threat of chytridiomycosis to wild populations of Archey's frog may not be severe. To confirm this, we recommend that the effect of the amphibian chytrid fungus should be evaluated in Archey's frog by a longitudinal study in an infected wild population such as that in the Whareorino Forest to correlate the presence of $\mathrm{Bd}$ in individual frogs over at least 3 yr based on clinical assessment, survival, growth and body condition parameters. Real time PCR using skin swabs is the best monitoring tool since bath testing for wild frogs is impractical as solutions have to be centrifuged soon after collection (Hyatt et al. 2007).

Acknowledgements. Reinholt Muller provided assistance with statistical analysis on weight gain. This study was approved by the University of Otago Animal Ethics Committee no. 88/06.

\section{LITERATURE CITED}

Banks C, McCracken H (2002) Captive management and pathology of sharp snouted dayfrogs, Taudactylus acutirostris, at Melbourne and Taronga zoos. In: Natrass AEO (ed) Frogs in the community. Proceedings of the Brisbane Symposium. Queensland Frog Society, East Brisbane, p $94-102$ 
Bell BD, Wassersug RJ (2003) Anatomical features of Leiopelma embryos and larvae: implications for anuran evolution. J Morphol 256:160-170

Bell BD, Carver S, Mitchell NJ, Pledger S (2004) The recent decline of a New Zealand endemic: How and why did populations of Archey's frog Leiopelma archeyi crash over 1996-2001? Biol Conserv 120:189-199

Berger L (2001) Diseases in Australian frogs. PhD thesis, James Cook University, Townsville

Berger L, Speare R, Daszak P, Green DE and others (1998) Chytridiomycosis causes amphibian mortality associated with population declines in the rain forests of Australia and Central America. Proc Natl Acad Sci USA 95: 9031-9036

Berger L, Speare R, Hines H, Marantelli G and others (2004) Effect of season and temperature on mortality in amphibians due to chytridiomycosis. Aust Vet J 82:31-36

Berger L, Marantelli G, Skerratt LF, Speare R (2005) Virulence of the amphibian chytrid fungus, Batrachochytrium dendrobatidis, varies with the strain. Dis Aquat Org 68: 47-50

Boyle DG, Boyle DB, Olsen V, Morgan JAT, Hyatt AD (2004) Rapid quantitative detection of chytridiomycosis (Batrachochytrium dendrobatidis) in amphibian samples using real-time Taqman PCR assay. Dis Aquat Org 60: 141-148

El-Mofty MM, Abdelmeguid NE, Sadek IA, Essawy AE, Abdel Aleem EA (2000) Induction of leukaemia in chloramphenicol-treated toads. La Revue de Sante de la Mediterranee Orientale 6:1026-1033

Green DM (1988) Antipredator behavior and skin glands in the New Zealand native frogs genus Leiopelma. NZ J Zool 15:39-46

Harris RN, James TY, Lauer A, Simon MA, Patel A (2006) Amphibian pathogen Batrachochytrium dendrobatidis is inhibited by the cutaneous bacteria of amphibian species. EcoHealth 3:53-56

Hyatt AD, Boyle DG, Olsen V, Boyle DB and others (2007) Diagnostic assays and sampling protocols for the detection of Batrachochytrium dendrobatidis. Dis Aquat Org 73: 175-192

IUCN (2008) Red list of threatened species. http://www. iucnredlist.org, accessed 20 February 2009

Kriger KM, Hero JM (2006) Survivorship in wild frogs infected with chytridiomycosis. EcoHealth 3:171-177

Longcore J (2000) Culture technics for amphibian chytrids: recognizing, isolating, and culturing Batrachochytrium dendrobatidis from amphibians. In: Moore $\mathrm{K}$, Speare R (eds) Getting the jump! on amphibian diseases. Conference and workshop compendium, 26-30 August 2000,

Editorial responsibility: Sven Klimpel,

Düsseldorf, Germany
Cairns, Queensland, p 52-54

Potter JS, Norman RJdeB (2006) Veterinary care of captive Archey's frogs, Leiopelma archeyi, at Auckland Zoo. Kakoka 13:19-26

Retallick RWR, Miera V (2007) Strain differences in the amphibian chytrid Batrachochytrium dendrobatidis and non-permanent, sub-lethal effects of infection. Dis Aquat Org 75:201-207

Rollins-Smith LA, Conlon JM (2005) Antimicrobial peptide defenses against chytridiomycosis, an emerging infectious disease of amphibian populations. Dev Comp Immunol 29: 589-598

Šadic E, Waldman B (2004) Rapid detection of amphibian chytrid fungus by PCR assay. In: Captivity, reintroduction and disease control technologies for amphibians. Amphibian Research Centre, Werribee, December 2004, http:// frogs.org.au/ppt/ErminSadic-RapidDetection/ (accessed 21 April 2007)

Schloegel LM, Hero JM, Berger L, Speare R, McDonald K, Daszak P (2006) The decline of the sharp-snouted day frog (Taudactylus acutirostris): the first documented case of extinction by infection in a free-ranging wildlife species? EcoHealth 3:35-40

Skerratt LF, Berger L, Speare R, Cashins S and others (2007) Spread of chytridiomycosis has caused the rapid global decline and extinction of frogs. EcoHealth 4:125-134

Smale A (2006) Archey's frog emergency translocationDOCDM-28159. Unpublished report. Department of Conservation, Waikato Conservancy, Hamilton

Waldman B (2004) Protecting NZ native frogs - captive facilities as a safe harbour. In: Captivity, reintroduction and disease control technologies for amphibians. Amphibian Research Centre, Werribee, December 2004, http://frogs. org.au/ppt/BruceWaldman-NewZealandFrogs/ (accessed 21 April 2007)

Waldman B, van de Wolfshaar KE, Klena JD, Andjic V, Bishop P, Norman RJdeB (2001) Chytridiomycosis in New Zealand frogs. Surveillance 28:9-11

> Woodhams DC, Alford RA, Marantelli G (2003) Emerging disease of amphibians cured by elevated body temperature. Dis Aquat Org 55:65-67

Woodhams DC, Rollins-Smith LA, Carey C, Reinert L, Tyler MJ, Alford RA (2006) Population trends associated with skin peptide defenses against chytridiomycosis in Australian frogs. Oecologia 146:531-540

Woodhams DC, Vrendenburg VT, Simon M, Billheimer D and others (2007) Symbiotic bacteria contribute to innate immune defenses of the threatened mountain yellowlegged frog, Rana muscosa. Biol Conserv 138:390-398

Submitted: January 7, 2008; Accepted: January 7, 2009 Proofs received from author(s): February 20, 2009 